\title{
REVOLUÇÃO PARADIGMÁTICA DA DECISÃO JUDICIAL Mediação, Conciliação, Arbitragem em Equidade
}

\author{
PARADIGMATIC REVOLUTION OF JUDICIAL DECISION \\ Mediation, Conciliation, Arbitraton in Equity
}

Carlos Aurelio Mota de Souza ${ }^{1}$

Recebido em: 11/02/2017

Aprovado em 18/07/2017

\section{RESUMO}

Enaltecida há séculos, dos gregos aos romanos e da Idade Média aos tempos moderno e contemporâneo, a equidade tem sido a mais bela expressão jurídica da justiça humanizadora do Direito. Aristóteles nos legou o conceito de epiêikeia como a justiça mais bela e perfeita ${ }^{2}$. Cícero e os jurisconsultos romanos a exaltaram como a aequitas, ars boni et aequi ${ }^{3}$. Os canonistas medievais

\footnotetext{
${ }^{1}$ Possui graduação em Geografia e História pela Universidade de São Paulo (1955), graduação em Direito Instituição Toledo de Ensino (1963), mestrado em Direito pela Universidade de São Paulo (1985) e doutorado em Direito pela Universidade de São Paulo (1989). Tem experiência na área de Direito, com ênfase em Teoria Geral do Direito, atuando principalmente nos seguintes temas: dignidade humana, ética, sociedade, direitos humanos e direito - filosofia
}

${ }^{2}$ Recordemos ainda uma vez o texto da Ética Nicomaqueia, Livro V, N. 11.

3 Jurisconsulto Celso: Jus est ars boni et aequi (O direito é a arte do bem e do justo). 
a chamaram de benignitas, magnanimitas, misericordia. São Tomás de Aquino a considerava a parte mais importante da justiça ${ }^{4}$; e no direito inglês, a equity. Nos séculos recentes, projetou-se nas legislações nacionais ${ }^{5}$, ingressou no Brasil pela Carta constitucional de 1824 (art. 179, inc. XVIII) e pela Constituição de 1934 (art. 113, inc. 37), que informou o CPC de 1939 (art. 114), com restrição no de 1973 (art. 127). Na atual reforma do Código de Processo Civil ${ }^{6}$ o instituto da equidade restou inscrito no art. 140, par. único, e nas expressões equitativo (art. 157, § $2^{\circ}$, sobre nomeação de peritos) e equitativa (art. 85, § $8^{\circ}$, sobre honorários advocatícios). Apesar dessas restrições legais, a equidade continua atuante nas regras pertinentes à Lei dos Juizados Especiais (art. $6^{\circ}$ ), da CLT (art. $8^{\circ}$ ), do CTN (art. 108), na prática das audiências de conciliação, mediação, na Lei da Arbitragem (art. $2^{\circ}$ ) e com apoio dos princípios gerais da Lei de Introdução; aliados ao bom senso e à prudência dos juízes, devem tais institutos contribuir para uma efetiva humanização dos processos, implícita no direito de acesso à justiça. Os magistrados se servirão de jurisprudência fundada em sólida doutrina para sustentação de decisões novas, pois a equidade, sendo conceito supralegal, metajurídico, pode prescindir de expressa autorização legislativa, quando se sobrepõe o cumprimento das finalidades sociais da lei e a promoção do bem comum.

\section{PALAVRAS CHAVE}

Decisão Judicial - Mediação - Conciliação - Arbitragem - Equidade.

\section{ABSTRACT}

Exalted for centuries, from the Greeks to the Romans and from the Middle Age to modern and con-temporary times, equity has been the most beautiful legal expression of the humanizing justice of the Law. Aristotle bequeathed to us the concept of epieikeia as the most beautiful and perfect justice. Cicero and the Roman jurisconsults exalted it as aequitas, ars boni et aequi. The medieval canonists called it benignitas, magnanimitas, misericordia. St. Thomas Aquinas considered it the most im-portant part of justice; and in En-

${ }^{4}$ Suma teológica, Q. II-II, 120

${ }^{5}$ Adotada no Código Civil suíço desde 1908.

${ }^{6}$ Lei N. 13.105, de 16/03/2015. 
glish law, equity. In recent centuries, it was projected in national legislations, it entered Brazil by the Constitutio-nal Charter of 1824 (article 179, inc. XVIII) and by the Constitution of 1934 (article 113, inc. 37), which informed the Civil Procedure Code of 1939 (article 114), with restriction in the Civil Procedure Code of 1973 (article 127). In the current reform of the new Brazilian Civil Procedure Code (2015), the institute of equity was inscribed in articles 140,157, § 2 (equitable, on appointment of experts) and in article $85, \S 8$ (equitative, on legal fees). Despite these restrictions, equity continues to operate in the rules pertaining to the Law of Special Courts (article 6), Labor Consolidation (article 8), Tributary Code (article 108), in the practice of conciliation hearings, mediation, in the Law of Arbitration (article 2) and with the support of the general principles of the Law Introduction; allied with the common sense and prudence of judges, should these institutes contribute to an effective humanization of processes, implicit in the right of access to justice. Magistrates will use jurisprudence based on solid doctrine to support new deci-sions, since equity, being a supralegal, metajuridic concept, can dispense with express legislative authorization, when it overcomes the fulfillment of the social purposes of the law and the promotion of the common good.

\section{KEYWORDS}

Judicial decision - Mediation - Conciliation - Arbitration - Equity. 


\section{INTRODUÇÃO - O paradigma da sentença judicial}

(Da mihi factum, dabo tibi ius) ${ }^{7}$

Em todo processo se encontra uma causa material: as questões de fato, particulares, específicas a cada caso; uma causa formal: as questões de direito, genéricas, universais; uma causa eficiente: aquele que julga, com competência ética, moral, jurídica; uma causa final: dar aquilo que é justo a cada um, dissolver a controvérsia, alcançar a paz social, com espírito de fraternidade ("para que não voltem a litigar ...").

Os códigos processuais de 1939 e 1973 instituíram um modelo para as sentenças, no formato tradicional, repristinado pelo atual $\mathrm{CPC}^{8}$ :

1- Relatório, síntese da inicial do autor, resposta do réu, provas colhidas e razões finais (com ênfase nos fatos e sutilezas das leis);

2 - Fundamentação ${ }^{9}$, sobre os fatos e questões que levam o juiz a "ponderar/ sopesar" qual ou quais vão dirimir o conflito, quais motivam seu senso jurídico, sua intuição para a solução mais justa. Neste campo o juiz exerce plenamente sua potestas, poder de polícia, direção do processo, ponderação e escolha dos fundamentos;

3 - Decisão, a atuação da formação jurídica e consciência humana do julgador, em que cabe aplicar a regra de ouro, ver os "outros" no processo como a si mesmo; aqui o julgador exerce sua auctoritas, o saber jurídico na aplicação da ratio decidendi, a razão suficiente, a fundamentação final da sentença, justa e concreta ${ }^{10}$.

A fundamentação do decisum, após sólida motivação sobre as questões de

\footnotetext{
${ }^{7}$ Dê-me o fato, (e) te darei o direito.

${ }^{8}$ Art. $489(458 / 73)$.

${ }^{9}$ Os Códigos de 1973 e o atual denominam esta fase de fundamentação, contrariamente à Constituição Federal que exige do juiz sejam "fundamentadas todas as decisões, sob pena de nulidade" (art. 93-IX), reservando a motivação para decisões administrativas (art. 93-X). Por isso entendemos, data venia, tratar-se aqui de mera motivação, pois o fundamento está reservado ao decisum, fase final da sentença. Cf. nosso Fundamentação das decisões judiciais como dever de justiça In: Ética, Direito, Justiça. S. Paulo, Letras Jurídicas, 2012, pg. 411. Revista Ibero Americana de Filosofia Política e Filosofia do Direito, PUCRS. Vol. 1, 2006, Pag.17.

10 "A normatividade não é mais o parâmetro definitivo e estável para resolução de conflitos". José Renato Nalini, A era da produtividade, O Estado de S. Paulo, 06/01/2015, pg. A2.
} 
fato e de direito, exige dos juízes uma mirada hacia arriba, considerando a transcendência da Justiça, e una mirada hacia abajo, quando descem à consideração das condições sociais subjacentes ao caso particular ${ }^{11}$.

No exercício desta auctoritas o conceito de equidade (espírito da lei) deve inspirá-los a ampliar seus paradigmas de valoração do processo, sem formalismos em excesso nem apego extremo às minúcias procedimentais. Importa-lhes apreciar as questões humanas implicadas nos casos particulares, mais que apegar-se às leis a aplicar.

Em inúmeras regras inovadoras do CPC perpassa o espírito da equidade, que deve subsumir-se nas decisões judiciais. Sua missão é extrair das questões o justo particular específico a cada caso, no mais puro ensinamento aristotélico ${ }^{12}$.

Embora presente como única norma expressa no CPC 2015 $5^{13}$, a equidade vem implícita em seu art. $8^{\circ}$ como princípio geral de direito ${ }^{14}$, ampliando dessa forma o art. $5^{\circ}$ da Lei de Introdução, ao avocar a função social da lei e o bem comum, à luz da dignidade da pessoa humana.

Os juízes estão conscientes de haver uma distância ética entre o legislador e o julgador: a vocação daquele é formular a letra das normas, enquanto a missão do julgador é decidir pelo espírito equitativo das leis, sempre que possível. No pensamento de Jean Cruet ${ }^{15}$, o magistrado-legislador é (como) o pretor romano, criador do direito pretoriano (p. 22); o juiz é um legislador à força (p. 43); e o ponto de vista abstrato do legislador não é o ponto de vista concreto do juiz (p. 55).

Alcançada a ratio decidendi, fundamento específico da sentença, o juiz humanista costuma indagar se o veredito satisfez aos interesses dos litigantes,

\footnotetext{
${ }^{11}$ Antonio Hernandez-Gil. El ordenamiento jurídico y la idea de justicia .Madrid, Real Academia de Jurisprudencia, 1981, p. 26

${ }^{12}$ Aristóteles. Ética a Nicômaco, L. V, Cap. 10.

${ }^{13}$ Art. 140 e par. único (art. 127 e par. ún. CPC73). Idem art. 721, par. ún., sobre Jurisdição voluntária.

${ }^{14}$ Ao aplicar o ordenamento jurídico, o juiz atenderá aos fins sociais e às exigências do bem comum, resguardando e promovendo a dignidade da pessoa humana e observando a proporcionalidade, a razoabilidade, a legalidade, a publicidade e a eficiência.

15 Jean Cruet, $A$ vida do direito e a inutilidade das leis. Paris, Flammarion, 1908. Ed. Portuguesa, Barcelona, Edit. Ibero-Americana,1938. 
aplicando a si mesmo a regra de ouro: se fosse minha a causa, estaria em paz com a decisão? Aceitaria esta sem recorrer? Mesmo em casos não conciliados previamente, constitui dever judicial decidir pela solução mais justa e menos danosa às partes, pois as decisões injustas causam danos, nem sempre reparáveis.

O novo juiz processualista deve, pois, armar-se de cultura, paciência e obstinação para enfrentar os males sociais que assolam a civilização, a dessacralização dos valores morais, a desconstrução das personalidades, a dissolução dos costumes sociais e cívicos, a desonra do corpo humano, o consumismo hedonístico, a trivialização do ensino, a alienação das mentes pela tecnologia das banalidades, o indiferentismo ético-político do povo, o reacionarismo populista reivindicatório, a cultura das superficialidades, o absenteísmo político às exigências públicas, o desrespeito e abandono às tradições históricas, enfim, a queda vertiginosa à infelicidade de viver. Embora pontuais, tais males têm força e destinação de se disseminarem globalmente.

\section{II - Revolução Axiológica Processual: novos métodos alternativos de solução de conflitos}

Conciliação, mediação, arbitragem, negociações, transações, representam modalidades de solução de litígios eticamente superiores aos métodos tradicionais; segundo Angel Ossorio, "as condições apreciáveis e indispensáveis para um bom procedimento judicial são: oralidade, publicidade, simplicidade e eficácia"16.

Sobre a matéria, dispõe o CPC 2015:

O conciliador [...] poderá sugerir soluções para o litígio, sendo vedada a utilização de qualquer tipo de constrangimento ou intimidação para que as partes conciliem. [...] A conciliação e a mediação são informadas pelos princípios da independência, da imparcialidade, da autonomia da vontade, da confidencialidade, da oralidade, da informalidade e da decisão informada ${ }^{17}$.

${ }^{16}$ El alma de la toga. Buenos Aires, Edit. Losada, 1940, p. 187.

${ }^{17}$ Cf. arts. 165 , §2 e 166; e 694 e 696, nas ações de família, do NCPC 
Recebida a petição inicial, o juiz designa de imediato audiência de conciliação ou mediação (art. 334), podendo haver mais de uma sessão necessárias à composição das partes $\left(\S 2^{\circ}\right)$. Também na audiência de instrução e julgamento o juiz tentará conciliar as partes, independentemente de tentativas anteriores (art. 359).

O mesmo ocorre nas ações de família, em que

[...] todos os esforços serão empreendidos para a solução consensual da controvérsia [...] para a mediação e conciliação (Art. 694), [...] em tantas sessões quantas sejam necessárias para viabilizar a solução consensual... (Art. 696).

No Código Civil se prevê igualmente o compromisso judicial ou extrajudicial para resolver litígios (art. 851), e questões de estado sem caráter patrimonial (art. 852) ou em contratos (art. 853).

\section{Conciliação e equidade}

Maria Inês Moura Santos Alves da Cunha ${ }^{18}$, em sua obra A equidade e os meios alternativos de solução de conflitos ${ }^{19}$ prenunciou a implementação ampla e efetiva de novos métodos, nomeadamente conciliação, mediação, arbitragem e juizados especiais, e o "ajustamento das lides coletivas perante o Ministério Público". Correta foi a autora ao fundamentar estes institutos na equidade ${ }^{20}, \mathrm{e}$ relacioná-la ao bem comum, como ressalta nas seguintes conclusões:

P. 67. Referir meios alternativos para solução de conflitos é mencionar também o uso da equidade na pacificação; p. 70. O bem comum é o supremo princípio diretor [...] sendo conceito [...] equivalente à equidade lato sensu; p. 72. As referências legais ao bem comum e aos fins sociais da lei, bem como à decisão mais justa e equânime [...] sinalizam uma autorização legal para o uso da equidade; p. 73. [...] sendo o bem comum (a) coordenação do bem de todos segundo princípio ético, exige do julgador [...] atenção às circunstâncias particulares, condições sociais, econômicas, políticas e culturais; p. 74. A atividade do juiz deve ser humanizadora e participativa, postando-se como intermediário dos valores prevalecentes na sociedade; p. 75. A decisão

\footnotetext{
${ }^{18}$ Desembargadora do Tribunal Regional do Trabalho de São Paulo (+2014).

${ }^{19}$ São Paulo, LTr, 2001. Dissertação de Mestrado em Direito Processual Civil na Universidade Mackenzie, orientada pelo Autor.

${ }^{20}$ Idem, Cap. 9.2, p. 117
} 
mais justa e equânime indicada pelo legislador é o justo revelado pela equidade, ou o equitativo de Aristóteles, dos romanos, da patrística, da escolástica e dos modernos [...] em um sentido de [...] complementaridade, em face das exigências de nossos tempos; p. 80. Dar prevalência ao equitativo em detrimento do legal significa ampliar o espectro da justiça para torná-la efetiva no âmbito das relações sociais e não apenas no nível jurídico e formal do discurso do Estado ${ }^{21}$. (Grifos nossos)

Pelo novo CPC os novos métodos de solução de conflitos revigoraram a conciliação e a mediação, minuciosamente detalhadas. Evidencia-se que o espírito que preside a ambas é o mesmo da equidade, a visão do homem e seu drama no processo e não a simples aplicação da letra das regras. $\mathrm{O}$ julgador moderno não é mais o servo ou escravo da lei (la bouche de la loi), mas o humanista de respeito à dignidade da pessoa (em seus direitos e deveres), que busca os fins sociais da lei e constrói a paz social, bem comum maior na sociedade (art. $8^{\circ}$, citado).

Na conciliação, nos casos em que não houve vínculo anterior entre as partes, o juiz estatal ou o particular sugerem, sem imposição ou constrangimento, a solução da pendência, que só se efetiva pelo livre acordo entre as partes ${ }^{22}$; na mediação, para casos em que existe vínculo anterior entre as partes, predomina a neutralidade e a imparcialidade do mediador, que não sugere, impõe ou interfere na solução e apenas auxilia as partes a alcançar a solução do conflito, gerando benefícios mútuos ${ }^{23}$. Nas duas hipóteses, o acordo entre os conflitantes resulta em uma transação, como também ocorre mediante advogados. ${ }^{24}$ Quanto à arbitragem ${ }^{25}$, o árbitro é juiz de fato e de direito, pode impor uma decisão por sentença (art. 12 da Lei), equiparada à heterocomposição judicial.

Há de se acrescentar a automediaçãa ${ }^{26}$, realizada pelos advogados das partes, fundada em princípios éticos e morais, em busca da eficiência e maximização

\footnotetext{
${ }^{21}$ Ibidem, pp. 145, 146

${ }^{22}$ Art. $165, \S 2^{\circ}$.

${ }^{23} \mathrm{Idem}, \S 3^{\circ}$.

$24 \mathrm{O}$ anterior Código de Ética da Advocacia, em seu art. $2^{\circ}$, inc. VI, já recomendava estimular a conciliação entre os litigantes, prevenindo,_sempre que possível, a instauração de litígios.

${ }^{25}$ Lei N 9.307/1996. No Senado Federal, pelo Projeto de Lei N 405/2013, propõe-se alteração da lei de arbitragem.

${ }^{26}$ Adalberto Simão Filho. Automediação: uma proposta para solução ética de conflitos. Revista da Faculdade de Direito FMU, n. 26, 2004, p. 141
} 
de valores, em que são evidentes os princípios éticos baseados na equidade.

Como se depreende destas soluções alternativas, ademais de atender à diminuição de ações judiciais, prevalece a intenção de se obter um resultado equitativo para as partes, o justo meio ou justa medida, preconizados por Aristóteles sobre a equidade.

\section{III - O novo paradigma de solução de conflitos ${ }^{27}$}

Thomas Khun celebrizou-se pela análise da mudança de paradigmas nas ciências, citando como exemplos a física de Aristóteles, a astronomia copernicana, a dinâmica newtoniana, a química de Boyle, a teoria da relatividade de Einstein. Segundo ele, produz-se uma revolução científica quando um novo paradigma substitui o paradigma tradicional e, a cada revolução, o ciclo se reinicia e o paradigma instaurado dá origem a um novo processo de ciência normal ${ }^{28}$.

Quando se fala, portanto, de mudança de paradigma, em geral tal mudança se refere a um momento revolucionário, tal como a referida revolução copernicana. Mas o que enfatizamos em relação à mudança no direito é a transformação de categorias jurídicas e a instauração de novos parâmetros, como é nos modos de conciliação e mediação.

Por que dizemos que tais categorias representam uma mudança de paradigma? Porque de um lado mostra-se um esgotamento do paradigma positivista clássico e de outro a abertura para soluções jurídicas que integram cessão consensual do direito e soluções equitativas de justa medida.

Sem prejuízo da jurisdição tradicional, o novo CPC disciplinou os institutos da conciliação, mediação e arbitragem visando acelerar o andamento das causas, oferecer justiça menos onerosa, aliviar processos nos tribunais, proceder à efetiva seleção dos conflitos, apaziguar os ânimos exaltados das partes.

Realizar a pacificação mediante métodos alternativos menos rígidos, constitui meta inteligente de se fazer justiça, otimiza o protagonismo dos juízes na direção do processo; versados em humanidades, serão sempre construtores da

\footnotetext{
${ }^{27}$ Arts. $165-175$ NCPC.

${ }^{28}$ Para Khun, as ciências evoluem por meio de paradigmas, "realizações científicas universalmente reconhecidas, que durante algum tempo fornecem soluções modelares para uma comunidade de praticantes de uma ciência". A estrutura das revoluções científicas. $7^{a}$. ed. S. Paulo, Perspectiva, 1991, p. 13.
} 
paz social, qualificados a promover a pacificação entre litigantes.

Jurista especializado em aplicação de leis, o juiz da pacificação é criativo, pioneiro, inovador de soluções extra e ante processuais. Na busca da pacificação judicial, por via da conciliação ou mediação, aplica o juiz a categoria da fraternidade, preconizada no Preâmbulo da Constituição: construir uma sociedade fraterna, pluralista, sem preconceitos.

Na realidade, ao buscar o cidadão a justiça mediante o processo, ele chama o Estado-juiz a intervir em sua vida e este assume o poder de tarifar sua liberdade, sua honra, seu salário, seu patrimônio. Nas conciliações as partes enxergam "o outro", estabelecem um contraditório de fato, exercem uma cidadania ativa, responsável, expressão de autêntica democracia participativa (CF) ${ }^{29}$; "a interferência do juiz, na conciliação, é uma forma, tal qual uma sentença, de fazer oportuna justiça, porque ele atua no aperfeiçoamento da equitatividade ... buscada pelas partes" ${ }^{\prime 30}$.

Os litigantes que ingressam no templo da Justiça podem enfrentar a impunidade, muitas vezes reiterada e a lentidão do Judiciário, o alto custo do processo e a imprevisibilidade na decisão. Em vez de simplesmente concretizar o justo pleiteado, o processo se torna finalidade em si mesmo. A causa formal (procedimentalista) e a eficiente (judicialista) acabam suplantando a causa final, que deveria expressar o fim do litígio mediante decisão justa, concreta, equânime e pacificadora.

Podemos vislumbrar no novo Código de Processo Civil que os renovados modelos de conciliação e mediação constituem um amplo paradigma a ser adotado em todas as audiências judiciais, segundo regras propícias à solução extrajudicial dos conflitos, haja vista a criação obrigatória de centros especializados por todos os tribunais (art. 165; CF art. 98, inc. I, e II, $\S 1^{\circ}$ ). Reconhece Elias Farah, renomado advogado trabalhista, que “... o importante e singular instituto jurídico conciliatório nas ações judiciais, é, sem dúvida, um dos meios mais promissores de evitar processos e ilidir conflitos" ${ }^{\prime 31}$.

\footnotetext{
29 José Renato NALINI, O Que Pensar da Justiça? In: Ética para o Juiz. Um olhar externo. S. Paulo, Quartier Latin, 2014, p. 78

${ }^{30}$ Elias Farah. Cidadania. São Paulo, Juarez de Oliveira, 2001, p. 331.
} 
Esta disponibilidade para conciliar e mediar demandas permite ao juiz a aplicação constitucional da fraternidade, como espírito imanente à conciliação: petição inicial e resposta iniciaram o diálogo conciliatório; as questões foram lançadas para debates; a motivação pelos fatos e normas invocados permite equilibrar reivindicações extremadas; as razões pessoais, bem ponderadas, levam a amenizar os ânimos, abrem-se as mentes para particularidades não suspeitadas, caem distâncias psicológicas, aproximam-se os contendores; as partes se reconhecem uma à outra, em termos pessoais e jurídicos.

A palavra do conciliador/mediador é doutoral, tem ares de sacralidade, as partes confiam na imparcialidade do expert que vai orientá-los à decisão. Ao longo das audiências elas amadurecem e esclarecem o juiz na compreensão das raízes da controvérsia. Desde a leitura das primeiras peças o conciliador/ mediador busca compreender o espírito dos que litigam, a razão psicológica da contenda e por quais razões evitaram um confronto prévio ao litígio judicial.

Qual deve ser a experiência exigida do juiz conciliador de conflitos nos apresenta Elias Farah:

... a neutralização dos ímpetos das partes precisa ser habilmente induzida por recomendações de um mediador paciente, equidistante, justo, qualificado e interessado, capaz de um diálogo conciliador, comedido, sem arrogância, encarnado na figura respeitável do juiz. ${ }^{32}$

No curso do processo, é vezeiro que audiências formais sejam adiadas por circunstâncias várias, adiantado da hora, falta de testemunhas, petição das partes, e o tempo passa. Por que não adiar conciliações até se alcançar um veredito consensualmente justo, superior a uma sentença recorrível? Aqui, o tempo é lucro, não mera protelação.

Quanta vez se assiste, ao final de conciliações e mediações bem sucedidas, litigantes empedernidos se confraternizarem, refazendo relacionamentos, afastando rancores e agradecendo ao conciliador ou mediador! Saem gratificados pelos ganhos e o juiz pelo dever cumprido. O conciliador/mediador é o juiz da fraternidade, o humanista que exerce a cidadania na democracia participativa, que atua em benefício da paz social e do bem comum, resguardando e promovendo as pessoas, como exigências éticas e constitucionais.

\footnotetext{
${ }^{31}$ Idem, p. 329

32 Ibidem, p. 331.
} 
É o julgador equânime, que vê e aplica a lei segundo o espírito de equidade; quando concilia ou media fundamenta-se mais na dignidade das pessoas do que no direito estrito, visando a construção daquela sociedade fraterna, justa e solidária, objeto do Bem comum (Preâmbulo da Constituição).

\section{Vantagens e desvantagens da conciliação e mediação}

Dentre as desvantagens das práticas conciliatórias avulta a recusa injustificada das partes, temerosas de um confronto pessoal ou constrangimentos pelo juiz ${ }^{33}$; a reação de advogados que insistem na litigiosidade do contraditório judicialista e pragmático; a falta de preparação psicológica das partes; conta igualmente a reduzida vocação de alguns juízes para estabelecerem diálogos, às vezes exaustivos, indisposição temperamental, despreparo, arrogância, falta de humildade, irritabilidade para negociação.

Já as vantagens superam: as conciliações promovem a celeridade e o arquivamento de inúmeras causas; a audiência é exercício de humanização do processo; estabelece-se um contraditório pessoal, real, não oficioso e formalista; haverá sempre economia de custas pela redução do processo às provas já presentes; desburocratizam-se os procedimentos pela oralidade informal, reduzindo o acordo a uma folha de papel; o despacho inicial pode e deve sugerir a conciliação prévia, com indicação de subsequentes ${ }^{34}$.

Tenha-se em mente os propósitos salutares do novo Código para reduzir a morosidade processual, a litigiosidade recursal e a economia de custos do processo, em prestígio do justo acesso e humanização da justiça, garantias fundamentais da Constituição. Igualmente a busca do aperfeiçoamento dos juízes, através das Escolas da Magistratura, bem como o estímulo do Tribunal de Justiça de São Paulo a esses paradigmas.

\footnotetext{
${ }^{33}$ Art. 165, § 20: "O conciliador ... poderá sugerir soluções para o litígio, sendo vedada a utilização de qualquer tipo de constrangimento ou intimidação para que as partes conciliem”.

${ }^{34}$ As partes comparecerão à audiência para tentativa de conciliação prévia (art. 334). Se necessárias, serão realizadas audiências subsequentes $\left(\S 2^{\circ}\right)$.
} 


\section{Conciliação e mediação em Cartórios}

A Constituição Federal preconizou que as controvérsias de âmbito interno deveriam ser resolvidas através de conciliação e pacificação por meios não convencionais ${ }^{35}$. O Conselho Nacional de Justiça $(\mathrm{CNJ})$, à sua vez, propôs a adoção, pelos Tribunais, de modelos aptos à solução pacificadora de conflitos, de forma a eliminar a sobrecarga de processos, recursos e execuções na Justiça ${ }^{36}$.

Como vimos, o CPC de 2015 ampliou as normas anteriores sobre conciliação e mediação (arts. 165 a 175). Através destes meios as partes podem dialogar e chegar a um entendimento que satisfaz seus interesses, mediante o cumprimento do acordo, válido como sentença judicial.

Referidos métodos extrajudiciais facilitam ao cidadão escolher a melhor forma de resolver suas contendas com os melhores benefícios. Cabe à sociedade valorizar estes meios e desenvolver uma nova cultura para solução de questões litigiosas. Nesta linha de atuações, os cartórios paulistas foram autorizados a praticar atos alternativos para melhor acesso à Justiça, desafogando o Poder Judiciário do acúmulo de processos, possibilitando maior agilidade e efetividade na resolução dos conflitos ${ }^{37}$.

O Estado de São Paulo foi pioneiro ao estender aos cartórios a via extrajudicial, mediante lavratura de atos de conciliação e mediação ${ }^{38}$, constituimdo-se

${ }^{35}$ A União e os Estados criarão juizados especiais para conciliação e juizados especiais federais (CF, art. 98 , inc. I, e $\left.I I, \S 1^{\circ}\right)$.

${ }^{36}$ Pela Resolução n 125/2010, o CNJ estabeleceu a obrigatoriedade de se implementar a conciliação e a mediação por todos os tribunais do País; disciplina mínima para a atividade dos mediadores e conciliadores, como critérios de capacitação, treinamento e atualização permanente; confidencialidade, imparcialidade e princípios éticos no exercício da função dos mediadores e conciliadores; estratégias para geração da nova mentalidade e da cultura da pacificação e controle pelo Judiciário dos serviços extrajudiciais de mediação e conciliação.

${ }^{37}$ É corrente que a sentença judicial não resolve o conflito. Parecer da Corregedoria Geral do Tribunal de Justiça de São Paulo (n 178/2013-E, de 6 de junho de 2013), enfatizou que "o magistrado, vinculado às leis e às provas trazidas aos autos, termina por prolatar decisão que não agrada nem ao autor nem ao réu, ao passo que, na conciliação, participando diretamente das tratativas, os envolvidos já sabem de antemão o que poderão ganhar e perder, esquivando-se de eventual descontentamento com a sentença judicial e da prorrogação da lide até o final julgamento dos recursos".

${ }^{38}$ As serventias extrajudiciais estão autorizadas pelo Provimento a lavrarem atos de conciliação e mediação em casos que envolvam direitos patrimoniais disponíveis, relacionados à compra e venda de imóveis, acidentes de trânsito, dívidas bancárias e questões societárias. Além do cidadão comum, pessoas jurídicas e empresários individuais também podem usufruir do serviço. 
em eficaz ferramenta para a desjudicialização, a exemplo dos resultados da Lei 11.441/07, que possibilitou a lavratura de separações, divórcios e inventários pelos Tabeliães de Notas $^{39}$.

Vimos que o instituto da conciliação, ora enfatizado pelo novo CPC, sempre foi de aplicação obrigatória no sistema judicial trabalhista, pelos princípios imperativos na solução dos conflitos laborais pela CLT (Arts. 764, $\left.\S \S 1^{\circ}, 2^{\circ}, 3^{\circ}\right)^{40}$.

Há de se louvar a preocupação do legislador de 1943, atribuindo aos juízes trabalhistas "ampla liberdade na direção do processo", velando "pelo andamento rápido das causas", renovada preocupação do legislador processual (Art. 765), o que bem justifica serem os juizados e tribunais trabalhistas denominados "justiça de equidade".

\section{Lei da Arbitragem ${ }^{41}$}

Foi estabelecido no art. $2^{\circ}$ que a arbitragem poderá ser de direito ou de equidade, a critério das partes, devendo constar da sentença se os árbitros julgaram por equidade (art. 26).

É característica da arbitragem, portanto, a utilização de um critério arbitral de julgamento que não seja estritamente legal, mas entendido pelo árbitro como sendo o mais justo, não podendo as partes se furtar ao resultado da decisão. Assim, arbitragem, mediação e conciliação constituem paradigmas instrumentais para a pacificação de conflitos de natureza civil, comercial e trabalhista, de forma rápida, amigável e informal, fora das lindes do Poder Judiciário.

Um dos mais altos fins alcançados pela aplicação da equidade consiste na humanização da Justiça, que exige um processo orientado pela oralidade, simplicidade, informalidade, economia processual e celeridade, como preconizado no art. $2^{\circ}$ da Lei dos Juizados Especiais.

\footnotetext{
${ }^{39}$ Os notários, registradores e prepostos autorizados a realizarem sessões de mediação e conciliação deverão adotar o Código de Ética de Conciliadores e Mediadores (Anexo III da Resolução n 125, do CNJ). Cf. Jornal do Notário. São Paulo, N. 155, mai/jun 2013, pp. 25-29.

${ }^{40}$ Art. 764. "Os dissídios individuais ou coletivos submetidos à apreciação da Justiça do Trabalho serão sempre sujeitos à conciliação. $\S 1^{\circ}$. Para efeito deste artigo, os juízes e Tribunais do Trabalho empregarão sempre os seus bons ofícios e persuasão no sentido de uma solução conciliatória dos conflitos. $\S 2^{\circ}$. Não havendo acordo, o juízo conciliatório converter-se-á obrigatoriamente em arbitral, proferindo decisão na forma prescrita neste Título. $\S 3^{\circ}$. É lícito às partes celebrar acordo que ponha termo ao processo, ainda mesmo depois de encerrado o juízo conciliatório". (Grifos nossos)

${ }^{41}$ Lei n 9.307, de 23 de setembro de 1996.
} 


\section{Conclusões}

Aduziremos as seguintes observações metodológicas às análises ora expostas:

$1^{\circ}$ ) os conceitos de equidade, como emanação do direito natural e como critério de julgamento, podem se sobrepor, porquanto ser equânime (dever natural do juiz) não é excepcional, pois está implícito no próprio ato do juízo, constituindo um direito-dever natural do julgador, que independe do sistema jurídico e pode ser exercido apesar dele;

$2^{\circ}$ ) bem por isso, excluída a equidade cerebrina ou de tipo alternativo, os demais conceitos serão sempre um dever da função do magistrado, apenas se distinguindo as funções explicitadas pela lei e as implícitas no ordenamento; assim como não pode haver uma regra jurídica que não seja moral, também não pode deixar de ser aplicada equitativamente, sempre que couber.

Do exposto se constata que o conceito de equidade, aplicado nas conciliações, mediações e arbitragens, longe de ser considerado supérfluo ou despiciendo, é historicamente considerado pela maioria dos juristas, com fundamento nas leis introdutória, processual e trabalhista, e aplicado com frequência, implícita ou explicitamente por árbitros e magistrados, orientados pelos conceitos de justiça social e bem comum, de raízes aristotélico-tomistas e jusnaturalistas.

\section{REFERÊNCIAS}

\section{ARISTÓTELES. Ética a Nicômaco, L. V, Cap. 10.}

CRUET, Jean, A vida do direito e a inutilidade das leis. Paris, Flammarion, 1908. Ed. Portuguesa, Barcelona, Edit. Ibero-Americana,1938.

FARAH, Elias. Cidadania. São Paulo, Juarez de Oliveira, 2001. 
HERNANDEZ-GIL, Antonio. El ordenamiento jurídico y la idea de justicia. Madrid, Real Academia de Jurisprudencia, 1981.

KHUN, Thomas. A estrutura das revoluções científicas. $7^{a}$. ed. S. Paulo, Perspectiva, 1991.

SOUZA, Carlos Aurélio Mota de. Fundamentação das decisões judiciais como dever de justiça In: Ética, Direito, Justiça. S. Paulo, Letras Jurídicas, 2012. Revista Ibero Americana de Filosofia Política e Filosofia do Direito, PUCRS. Vol. 1, 2006.

NALINI, José Renato, A era da produtividade, O Estado de S. Paulo, A2, 06/01/2015.

O Que Pensar da Justiça? In: Ética para o Juiz. S. Paulo, Quartier Latin, 2014.

OSSORIO, Angel. El alma de la toga. Buenos Aires, Edit. Losada, 1940.

SIMÃO FILHO, Adalberto. Automediação: uma proposta para solução ética de conflitos. Revista da Faculdade de Direito FMU, n. 26, 2004. 